\title{
Verlängerung Zulassungsstopp - Informationen über den Vernehmlassungs- entwurf vom 21. März 2005
}

\author{
Hanspeter Kuhn ${ }^{a}$ Lucia Rabia ${ }^{b}$
}

a Fürsprecher, stv. Generalsekretär FMH

b Fürsprecherin, stv. Leiterin FMHRechtsdienst

1 Kuhn Hp. KVG-Revision - wo stehen wir heute? Zulassungsstopp und einige andere Bestimmungen verlängert, Rest in parlamentarischer Diskussion oder an den Bundesrat zurückgewiesen. Schweiz Ärztezeitung 2004;85(49):2622-3.

2 Es geht bei dieser Regelung nur um die Tätigkeit zu Lasten der sozialen Krankenversicherung. Das Bundesrecht sieht kein Dahinfallen der Praxisbewilligung für andere Bereiche (UV, MV, IV,

Selbstzahler) vor.

Hingegen kennen einige Kantone (BS, BL, OW, SH, SZ, UR, ZG) in ihrem kantonalen Gesundheitsgesetz Bestimmungen für das Dahinfallen der gesamten Praxisbewilligung. Die Idee dieser Kantone lässt sich grob etwa so zusammenfassen: «Wir wollen wissen, wer wirklich in eigener Praxis Patienten behandelt, egal für welchen Kostenträger. Alle anderen sollen die Bewilligung

- entweder zurückgeben (zum Beispiel aus Altersgründen);

- oder sistieren (zum Beispiel bei längerem Einsatz im Ausland).»

3 Siehe Ziff. 3.1.3. der Erläuterungen «Teilzeitarbeit: Bei der Ausarbeitung der heute geltenden Vorschriften wurde im Hinblick auf eine möglichst einfache Umsetzung bewusst auf die Berücksichtigung des Arbeitspensums verzichtet. [...] Weder über Sollstunden noch über die Abrechnungshöhe lässt sich ein Kriterium finden, welches im Rahmen dieser Verordnung praktikabel und kurzfristig umsetzbar wäre. Daher wird auf eine Regelung verzichtet, zumal auch in den gesetzlichen Bestimmungen keine Voraussetzung einer Vollzeittätigkeit für selbstständig erwerbende Personen besteht.»

\section{Ausgangslage}

Der bisherige KVG-Zulassungsstopp würde am 3. Juli 2005 auslaufen. Weil die KVG-Revision noch nicht zu Ende geführt ist, hat das Parlament mit einer Zwischenrevision (vorgestellt in SÄZ 49/2004 [1]) dem Bundesrat erlaubt, den Zulassungsstopp um maximal 3 Jahre zu verlängern, also längstens bis zum 3. Juli 2008. Und das Parlament hat vorgesehen, dass der Bundesrat eine Frist festlegt für das Dahinfallen nicht benützter Praxisbewilligungen für die Tätigkeit zu Lasten der sozialen Krankenversicherung [2].

\section{Verordnungsentwurf}

Am 21. März 2005 hat der Bundesrat den Entwurf in Vernehmlassung gegeben. Die wichtigsten Informationen:

- Der Zulassungsstopp soll bis längstens 3. Juli 2008 verlängert werden.

- Schon erteilte, aber nicht benützte Praxisbewilligungen sollen am 4. Januar 2006 dahinfallen; die Kantone sollen diese Frist verlängern können.

- Die revidierte Verordnung soll nahtlos am 4. Juli 2005 in Kraft treten.

\section{Weitere Hinweise}

Es ist ein Vernehmlassungsentwurf. Wir wissen nicht, ob der Bundesrat nach der Vernehmlassung daran noch etwas ändern wird. Und: Die Er- läuterungen zum Entwurf äussern sich nicht zur Frage, was Ärztin und Arzt konkret tun müssen, damit die Praxisbewilligung für die Behandlung von Krankenkassenpatienten nicht dahinfällt. Klar ist nur: Der Bund unterscheidet nicht zwischen Vollzeit- und Teilzeitpraxis [3]. Wir gehen deshalb, wie schon in SÄZ 49/2004, S. 2622f., davon aus, dass die sicherste Lösung ist,

- rechtzeitig,

- in eigenem Namen

- und auf eigene Rechnung

Krankenkassenpatienten zu behandeln.

Wenn Behandlungen noch vor dem Termin (also vor dem 4. Januar 2006, falls der Bundesrat bei dieser Frist bleibt) auch noch abgerechnet werden, vereinfacht dies wohl rein administrativ die Arbeit der kantonalen Gesundheitsdirektion, die am Ende entscheiden muss, wessen Praxisbewilligung nun wegen Nichtbenützung für Krankenkassenpatienten dahinfällt. Rechtlich kann es aber nach unserer Auffassung nicht auf den Versand der Rechnungen ankommen. Es muss genügen, dass man rechtzeitig Krankenkassenpatienten in eigenem Namen und auf eigene Rechnung behandelt hat.

Sie finden den vollständigen Text des Verordnungsentwurfs, der Erläuterungen sowie der neuen Höchstzahlen pro Kanton und Fachgebiet auf der Website der FMH (www.fmh.ch $\rightarrow$ Unsere Dienstleistungen $\rightarrow$ Recht $\rightarrow$ Links $\rightarrow$ Weiterentwicklung des KVG).

Vernehmlassungsfrist ist der 15. April 2005. Der Zentralvorstand der FMH wird seine Stellungnahme mit dem VSAO absprechen. 